\title{
Enhancement of Epithelial Barrier Function by Probiotics
}

\author{
Karen L. Madsen* \\ Division of Gastroenterology, University of Alberta Edmonton, Alberta, Canada
}

\begin{abstract}
Probiotics are microbial organisms that are administered in supplements or foods to enhance the well-being of the host. There exists substantial evidence that in a strain and dose-dependent manner, probiotics can modulate systemic and mucosal immune function, improve intestinal barrier function, alter gut microecology, and exert metabolic effects on the host. Several strains of Lactobacillus and Bifidobacterium are able to compete with pathogens for binding to intestinal epithelial cells, and can displace pathogens. Epithelial cell signalling pathways are stimulated by whole microbes, structural components, and microbial-produced metabolites. In particular, the NF-kB pathway is modulated by probiotics at many different levels with effects seen on I $\mathrm{BB}$ degradation and ubiquitination, proteasome function, and nuclearcytoplasmic movement of RelA through a PPAR-gamma dependent pathway. In a strain and dose-dependent manner, probiotic strains have been shown to alter tight junction protein expression and/or localization in both in vivo and in vitro models. Probiotics can also enhance gut barrier function via increased production of cytoprotective molecules such as heat-shock proteins. In addition, probiotics are able to prevent cytokine- and oxidant-induced epithelial damage by promoting cell survival. Lactobacillus GG and soluble factors (p75 and p40) released from LGG prevented epithelial cell apoptosis through activating anti-apoptotic Akt in a phosphatidylinositol-3'-kinase (PI3K)-dependent manner and inhibiting pro-apoptotic p38/MAPK activation. It is clear that host-microbial interactions at the gut mucosal surface are critical for health and overall homeostasis and probiotics may possibly be harnessed to enhance barrier function in order to maintain health and protect against disease.
\end{abstract}

Keywords: Epithelium, Lactobacillus, Bifidobacterium, Tight junctions.

\section{INTRODUCTION}

Probiotics are microbial organisms that are administered in supplements or foods to enhance the well-being of the host [1]. A growing body of work now exists describing the role of various probiotic strains in ameliorating chronic intestinal inflammation, diarrhoea, constipation, irritable bowel syndrome, and liver disease [2]. There exists substantial evidence that in a strain and dose-dependent manner, probiotics can modulate systemic and mucosal immune function, improve intestinal barrier function, alter gut microecology, and exert metabolic effects on the host [1]. Probiotic strains have been shown to enhance intestinal barrier function by stimulating mucus and antimicrobial peptide production [3-7]; increasing mucosal $\operatorname{Ig} \mathrm{A}$ responses [8]; enhancing tight junction protein expression and/or localization [9-18], preventing epithelial cell apoptosis [19] and by the induction of cytoprotective molecules [20].

Intestinal epithelial cells have both a barrier and immunomodulatory role in the gut through their interactions with each other and influence over underlying immune cells. Epithelial cell signalling pathways are stimulated by whole microbes, microbial structural components, and microbialproduced metabolites. In particular, the NF-kB pathway is modulated by probiotics at many different levels with probioticinduced effects seen on I $\kappa \mathrm{B}$ degradation and ubiquitination

*Address correspondence to this author at the University of Alberta, 7-142 Katz Group Center, Edmonton, Alberta, Canada T6G 2E1; Tel: (780) 492-5257;

E-mail: karen.madsen@ualberta.ca
[21-23], proteasome function [23, 24]; and nuclearcytoplasmic movement of RelA through a PPAR-gamma dependent pathway $[16,25]$. Effects of probiotics are not limited to live bacteria, but include modulation of cellular homeostasis by microbial DNA [23, 26, 27], soluble proteins released from live microbes $[10,20]$, cell wall structural components including polysaccharides [28, 29], and metabolites produced by probiotic fermentation of luminal nutrients [30].

\section{Competitive Exclusion and Mucus Secretion}

Several strains of Lactobacillus and Bifidobacterium are able to compete with pathogens for binding to intestinal epithelial cells, and are able to displace pathogens even if the pathogens have already attached [31-34]. Some strains of lactobacilli express human mucus-binding pili, which would enhance their ability for colonization [35]. Probiotic inhibition of pathogen adherence to epithelial cells is mediated partially by competition for lectin binding sites on glycoconjugate receptors on the brush border surface $[36,37]$. Probiotics also express microorganism-associated molecular patterns (MAMPS) that bind to the same pattern recognition receptors as pathogens do, thus preventing access via competitive exclusion [35]. Probiotics also induce mucus secretion, which would aid in preventing pathogenic bacterial adhesion $[4,7,38]$.

\section{Effects on Epithelial Tight Junctions}

In a strain and dose-dependent manner, numerous probiotic strains have been shown to directly alter tight junction 


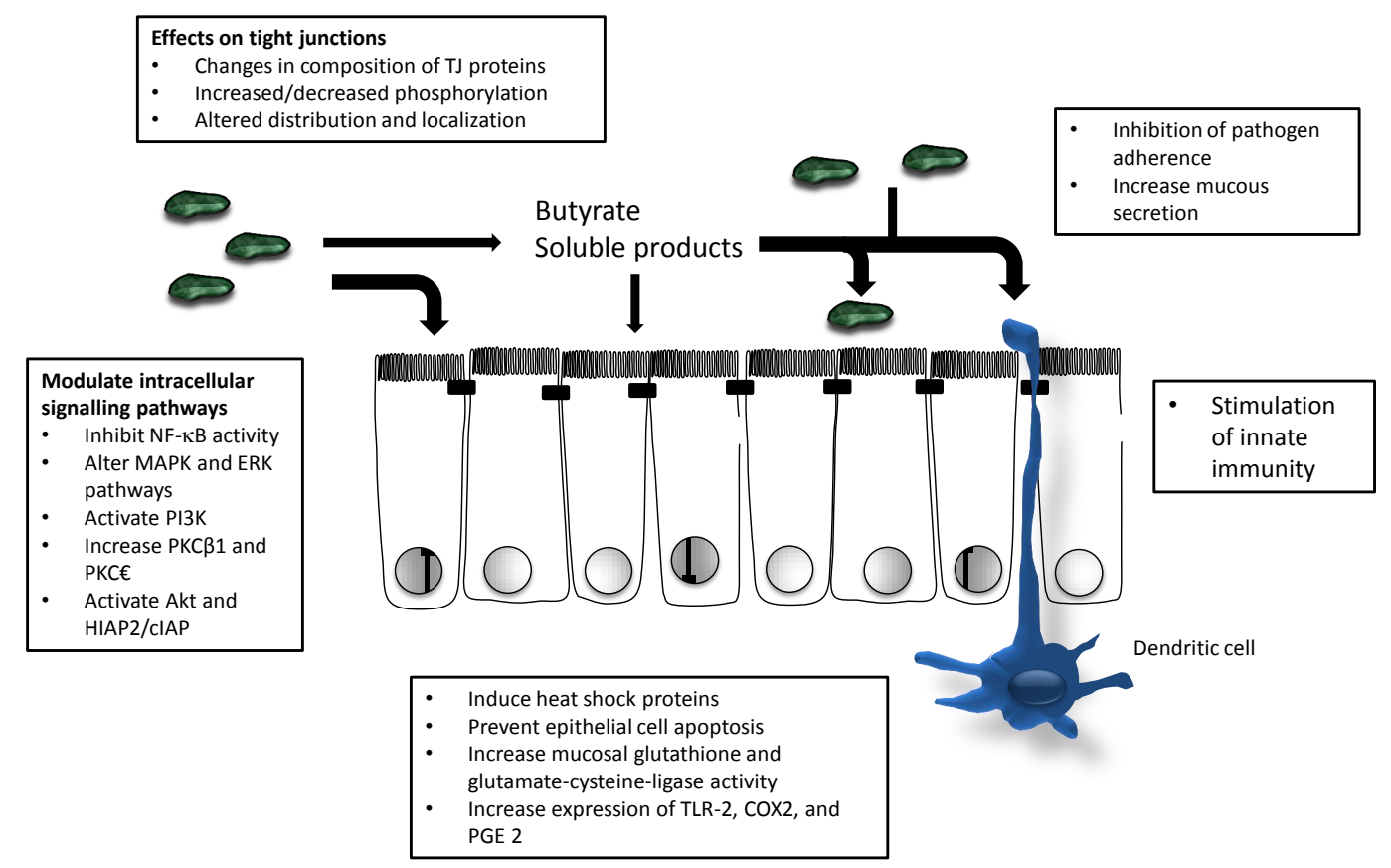

Fig. (1). An overview of mechanisms involved in probiotic-induced enhancement of epithelial barrier function. These include direct modulation of epithelial cell signaling pathways and tight junctions, as well as effects on microbial ecology and innate and adaptive immune function.

protein expression and/or localization in both in vivo and in vitro models [9-18, 39]. Resta-Lenert and Barrett [11] showed that Streptococcus thermophilus and Lactobacillus acidophilus both increased epithelial resistance of HT-29 and Caco-2 cells. The effect of these strains on epithelial resistance was accompanied by either maintenance (actin, ZO-1) or increased (actinin, occludin) levels of tight junctional protein phosphorylation [11]. Treatment of HT-29 and Caco-2 cells with $S$. thermophilus and L. acidophilus also resulted in an activation of p38, ERK, phosphatidylinositol 3-kinase (PI3K), and JNK pathways [11, 40]. In these studies, cultured medium and heat-killed bacteria did not alter resistance, indicating that live S. thermophilus and L. acidophilus were required. In a similar fashion, Lactobacillus rhamnosus and Bifidobacterium lactis increased epithelial resistance in conjunction with increased phosphorylation of ZO-1 and occludin [15]. In contrast, both live organisms and conditioned media from bacteria strains found in the probiotic mixture, VSL\#3, (Bifidobacterium longum, Bifidobacterium infantis, Bifidobacterium breve, Lactobacillus acidophilus, Lactobacillus casei, Lactobacillus delbrueckii subsp. bulgaricus, Lactobacillus. plantarum, Streptococcus salivarius subsp. Thermophilus) increased resistance of T84 cells, with Bifidobacterium infantis exerting the largest effect [41]. This increase in resistance was accompanied by decreased claudin- 2 protein expression and increased protein expression of ZO-1 and occludin [10]. $B$. infantis-conditioned medium increased levels of phosphoERK1 and 2 and decreased phospho-p38, suggesting a role for the MAPK pathway [10]. B. infantis conditioned media was also effective in reducing intestinal permeability and improving disease in a mouse model of colitis [10].

Gene expression studies [12] have demonstrated that Lactobacillus plantarum MB452 altered expression levels of numerous tight junction-related genes, including those encoding occludin and cytoskeleton anchoring proteins. Tubulin and proteasome associated genes were also altered by L. plantarum [12].

E. coli Nissle 1917 has also demonstrated direct effects on tight junctional proteins in epithelial cells. Zyrek et al., [13] showed that $E$. coli Nissle increased resistance of T84 cells and increased expression and tight junction localization of ZO-2. Germ-free mice colonized with $E$. coli Nissle had an upregulation of ZO-1 in intestinal epithelial cells at both the mRNA and protein levels [9]. Interestingly, a recent study showed both E.coli Nissle conditioned media and isolated LPS from $E$. coli Nissle to have similar effects on increasing epithelial resistance [28].

Various factors, including oxidative stress, pathogenic organisms, and pro-inflammatory cytokines, can reduce epithelial barrier function, [16, 18, 39, 42]. A common finding is that probiotics are able to protect tight junctions from disruptions induced by these factors. IFN $\gamma$ and TNF $\alpha$ have been shown to alter barrier function in an apoptosisindependent manner by inducing an internalization of tightjunction transmembrane proteins, rearranging the internal actin cytoskeleton, causing a redistribution of JAM-1 from membrane raft-containing fractions, and inducing a redistribution of the adherent junction protein E-cadherin [43]. IFN $\gamma$ and $\mathrm{TNF} \alpha$ also reduce occludin and ZO-1 gene expression in HT-29/B6 cells, suggesting that cytokines can also modulate barrier function at gene level [44]. Pretreatment of T84 cells with $B$. infantis-conditioned medium prevented a decrease in resistance induced by TNF- $\alpha$ or IFN- $\gamma$ treatment, and was blocked by ERK inhibition [10]. A similar finding was seen by Resta-Lenert, where pretreatment of T84 cells with $S$. thermophilus and $L$. acidophilus also prevented the deleterious effects of IFN- $\gamma$ or TNF- $\alpha$ treatment [40]. This protection was associated with ERK, p38, and PI3K 
activation by the probiotic [40]. Donato et al., [16] showed that Lactobacillus rhamnosus GG attenuated IFN $\gamma$ and TNF $\alpha$ induced barrier disruption in $\mathrm{Caco} 2$ cells by reducing the nuclear translocation of p65. Lactobacillus GG and LGGderived soluble proteins (p40 and p75) maintained epithelial barrier function in the presence of hydrogen peroxideinduced disruption by increasing membrane translocation of ZO-1, occludin, PKC $\beta 1$, and PKC $€$ in an extracellular signal-related kinase (ERK1/2) and mitogen-activated protein kinase (MAPK)-dependent manner [45].

Similar results are seen in animal models. In two different animal models of colitis, (IL-10 deficient mice and mdr1a null mice), treatment with VSL\#3 or S. thermophiles and $L$. acidophilus respectively resulted in a decrease in gut permeability and improvement of disease [41, 46]. In an animal model of acute pancreatitis, pre-treatment of rats with a multispecies probiotic mixture (Lactobacillus acidophilus (W70), Lactobacillus casei (W56), Lactobacillus salivarius (W24), Lactococcus lactis (W58), Bifidobacterium bifidum (W23), and Bifidobacterium lactis (W52) protected against an oxidative stress-induced increase in gut permeability, bacterial translocation, epithelial cell apoptosis, and tight junction protein disruption [39]. This was associated with a probiotic-induced increase in mucosal glutathione and glutamate-cysteine-ligase activity [39]. An interesting study by Pagnini et al., [22] demonstrated that treatment of SAMP1/YitFc (SAMP) mice with chronic gut inflammation with VSL\#3 (Bifidobacterium longum, B. infantis, and B. breve, L. Acidophilus, L. casei, L. delbrueckii subsp. l bulgaricus and L. planetarium, Streptococcus salivarius subsp. Thermophilus) resulted in a decrease in gut permeability in conjunction with a stimulation of innate immunity as evidenced by enhanced TNF $\alpha$ secretion.

\section{Cytoprotective Molecules}

Probiotics can also enhance epithelial gut barrier function via increased production of cytoprotective molecules such as heat-shock proteins. Heat-shock proteins are constitutively expressed in epithelial cells and are induced in cells by stress in order to help maintain homeostasis [24]. Soluble factors released from Lactobacillus GG induced cytoprotective heat shock protein synthesis in intestinal epithelial cells in a p38and JNK/MAPK-dependent manner [20]. Quorum-sensing molecules secreted by Bacillus subtilis also induced epithelial expression of cytoprotective heat shock proteins [47].

\section{Effects on Apoptosis}

In addition to their effects on tight junction proteins, probiotics are also able to prevent cytokine- and oxidantinduced epithelial damage by promoting cell survival. Lactobacillus GG and soluble factors (p75 and p40) released from LGG prevented epithelial cell apoptosis through activating anti-apoptotic Akt in a phosphatidylinositol-3'-kinase (PI3K)-dependent manner and inhibiting pro-apoptotic p38/MAPK activation [48, 49]. This reduction in apoptosis would help to maintain epithelial barrier integrity and increase resistance to pathogens by reducing breaks in the mucosal barrier. In an in vivo study, Lactobacillus plantarum $299 \mathrm{v}$ increased expression of members of the inhibitor of apoptosis protein family (HIAP2/cIAP) [3]. In another study, administration of Bifidobacterium bifidum increased expres- sion of TLR-2, COX2, and PGE 2 and significantly reduced apoptosis in the intestinal epithelium in a necrotizing enterocolitis (NEC) model [19]. Further, inhibition of COX2 signalling blocked the protective effect of B. bifidum suggesting that a probiotic-induced increased expression of COX2 and elevated production of PGE2 was responsible for the protection. This elevation of PGE2 production subsequently protected against epithelial cell apoptosis associated with NEC thus preserving intestinal barrier function. [19]

\section{Clinical Applications of Probiotics}

The ability of the gut epithelium to act as a barrier between the external environment and the closely regulated internal milieu is absolutely essential for human health [50]. When the gut barrier is disrupted, not only does a greater amount of microbial antigenic material transverse the gut, but the altered route of passage can also significantly alter the immunogenicity of the microbial antigen. Increased gut permeability is associated with several different human diseases, including inflammatory bowel disease [51], graft vs host disease[52], type 1 diabetes [53], and celiac disease [54]. Increased gut permeability also has a role in the pathogenesis of sepsis and multiple organ failure in patients following surgery or trauma [55]. Using probiotics to prevent and/or treat pro-inflammatory and oxidant induced breakdown in gut barrier function is an attractive therapeutic option. However, in various clinical trials, probiotics have been shown to reduce gut permeability under some conditions but not others [56]. In addition, probiotic-induced alterations in gut permeability are not always associated with changes or improvement in clinical symptoms [56]. It is clear that at this time, more studies are required to determine the exact relationship which exists between probiotic use, alterations in gut permeability, and clinical symptoms.

\section{CONCLUSION}

A barrier between luminal microorganisms and the host immune system is maintained through intestinal epithelial cells, mucus and anti-microbial production, and $\operatorname{IgA}$ secretion. In a strain-dependent manner, probiotics have the capacity to enhance gut barrier function through numerous different mechanisms. It is clear that host-microbial interactions at the gut mucosal surface are critical for health and overall homeostasis and further, that probiotics may be harnessed to enhance barrier function in order to maintain health and protect against disease. In the future, larger clinical trials will need to be carried out to determine how best to use probiotics in the prevention or treatment of various diseases. The particular strains of probiotics best suited to the treatment of specific diseases will need to be determined, along with the amount of bacteria to use, the time of dosing, and whether combinations or single strains are preferable.

\section{CONFLICT OF INTEREST}

None declared.

\section{ABBREVIATIONS}

$\begin{array}{ll}\mathrm{AJ} & =\text { Adherens junction } \\ \mathrm{ERK} & =\text { Extracellular signal regulated kinase } \\ \mathrm{IFN} & =\text { Interferon }\end{array}$




$\begin{array}{ll}\mathrm{I} \kappa \mathrm{B} & =\text { Inhibitor of kappaB } \\ \mathrm{JNK} & =\text { c-Jun N-terminal kinase } \\ \mathrm{LPS} & =\text { Lipopolysaccharide } \\ \text { MAPK } & \text { Mitogen-activated protein kinase } \\ \text { MAMP } & \text { Microbe-associated molecular patterns } \\ \text { NEC } & \text { Necrotizing enterocolitis } \\ \text { NF- } \mathrm{B} & =\text { Nuclear factor kappa } \mathrm{B} \\ \mathrm{TLR} & =\text { Toll-like receptor } \\ \mathrm{TNF} & =\text { Tumor necrosis factor } \\ \mathrm{ZO} & =\text { Zonula occludens }\end{array}$

\section{ACKNOWLEDGEMENTS}

None declared.

\section{REFERENCES}

[1] Shanahan F. Probiotics in perspective. Gastroenterology 2010; 139:1808-12.

[2] Sekirov I, Russell SL, Antunes LC, Finlay BB. Gut microbiota in health and disease. Physiol Rev 2010; 90: 859-904.

[3] Dykstra NS, Hyde L, Adawi D, et al. Pulse Probiotic administration induces repeated small intestinal MUC3 expression in rats. Pediatr Res 2011; 69: 206-11.

[4] Mack DR, Ahrne S, Hyde L, Wei S, Hollingsworth MA. Extracellular MUC3 mucin secretion follows adherence of Lactobacillus strains to intestinal epithelial cells in vitro. Gut 2003; 52: 827-33.

[5] Mondel M, Schroeder BO, Zimmermann K, et al. Probiotic E. coli treatment mediates antimicrobial human beta-defensin synthesis and fecal excretion in humans. Mucosal Immunol 2009; 2:166-72.

[6] Schlee M, Harder J, Koten B, Stange EF, Wehkamp J, Fellermann, K. Probiotic lactobacilli and VSL\#3 induce enterocyte betadefensin 2. Clin Exp Immunol 2008;151: 528-35.

[7] Caballero-Franco C, Keller K, De Simone C, Chadee K. The VSL\#3 probiotic formula induces mucin gene expression and secretion in colonic epithelial cells. Am J Physiol Gastrointest Liver Physiol 2007; 292: G315-22.

[8] Alberda C, Gramlich L, Meddings J, et al. Effects of probiotic therapy in critically ill patients: a randomized, double-blind, placebo-controlled trial. Am J Clin Nutr 2007; 85: 816-23.

[9] Ukena S, Singh A, Dringenberg U, et al. Probiotic Escherichia coli Nissle 1917 inhibits leaky gut by enhancing mucosal integrity. PLoS Biol 2007; 2:1308.

[10] Ewaschuk J, Diaz H, Meddings L, et al. Secreted bioactive factors from Bifidobacterium infantis enhance epithelial cell barrier function. Am J Physiol Gastrointest Liver Physiol 2008; 295: G1025-34.

[11] Resta-Lenert S, Barrett KE. Live probiotics protect intestinal epithelial cells from the effects of infection with enteroinvasive Escherichia coli (EIEC). Gut 2003; 52:988-97.

[12] Anderson RC, Cookson AL, McNabb WC, et al. Lactobacillus plantarum MB452 enhances the function of the intestinal barrier by increasing the expression levels of genes involved in tight junction formation. BMC Microbiol 2010; 10: 316.

[13] Zyrek AA, Cichon C, Helms S, Enders C, Sonnenborn U, Schmidt MA. Molecular mechanisms underlying the probiotic effects of Escherichia coli Nissle 1917 involve ZO-2 and PKCzeta redistribution resulting in tight junction and epithelial barrier repair. Cell Microbiol 2007; 9: 804-16.

[14] Eun CS, Kim YS, Han DS, Choi JH, Lee AR, Park YK. Lactobacillus casei prevents impaired barrier function in intestinal epithelial cells. APMIS 2011; 119: 49-56.

[15] Mathias A, Duc M, Favre L, Benyacoub J, Blum S, Corthesy B. Potentiation of polarized intestinal Caco-2 cell responsiveness to probiotics complexed with secretory IgA. J Biol Chem 2010; 285: 33906-13.

[16] Donato KA, Gareau MG, Wang YJ, Sherman PM. Lactobacillus rhamnosus GG attenuates interferon-\{gamma $\}$ and tumour necrosis factor-alpha-induced barrier dysfunction and pro-inflammatory signalling. Microbiology 2010; 156: 3288-97.

[17] Chen HQ, Yang J, Zhang M, et al. Lactobacillus plantarum ameliorates colonic epithelial barrier dysfunction by modulating the apical junctional complex and PepT1 in IL-10 knockout mice. Am J Physiol Gastrointest Liver Physiol 2010; 299: G1287-97.

[18] Zhou Y, Qin H, Zhang M, et al. Lactobacillus plantarum inhibits intestinal epithelial barrier dysfunction induced by unconjugated bilirubin. Br J Nutr 2010; 104: 390-401.

[19] Khailova L, Mount PSK, Arganbright KM, Halpern MD, Kinouchi T, Dvorak B. Bifidobacterium bifidum reduces apoptosis in the intestinal epithelium in necrotizing enterocolitis. Am J Physiol Gastrointest Liver Physiol 2010; 299: G1118-27.

[20] Tao Y, Drabik KA, Waypa TS, et al. Soluble factors from Lactobacillus GG activate MAPKs and induce cytoprotective heat shock proteins in intestinal epithelial cells. Am J Physiol Cell Physiol 2006; 290: C1018-30.

[21] Neish AS, Gewirtz AT, Zeng H, et al. Prokaryotic regulation of epithelial responses by inhibition of IkappaB-alpha ubiquitination. Science 2000; 289: 1560-3.

[22] Pagnini C, Saeed R, Bamias G, Arseneau KO, Pizarro TT, Cominelli F. Probiotics promote gut health through stimulation of epithelial innate immunity. Proc Natl Acad Sci USA 2010; 107: 454-9.

[23] Jijon $\mathrm{H}$, Backer $\mathrm{J}$, Diaz $\mathrm{H}$, et al. DNA from probiotic bacteria modulates murine and human epithelial and immune function. Gastroenterology 2004; 126: 1358-73.

[24] Petrof EO, Kojima K, Ropeleski MJ, et al. Probiotics inhibit nuclear factor-kappaB and induce heat shock proteins in colonic epithelial cells through proteasome inhibition. Gastroenterology 2004; 127: 1474-87.

[25] Kelly D, Campbell JI, King TP, et al. Commensal anaerobic gut bacteria attenuate inflammation by regulating nuclear-cytoplasmic shuttling of PPAR-gamma and RelA. Nat Immunol 2004; 5: 104-12.

[26] Ewaschuk JB, Backer JL, Churchill TA, Obermeier F, Krause DO, Madsen KL. Surface expression of Toll-like receptor 9 is upregulated on intestinal epithelial cells in response to pathogenic bacterial DNA. Infect Immun 2007; 75: 2572-9.

[27] Lee J, Rachmilewitz D, Raz E. Homeostatic effects of TLR9 signaling in experimental colitis. Ann NY Acad Sci 2006; 1072: 351-5.

[28] Stetinova V, Smetanova L, Kvetina J, Svoboda Z, Zidek Z, Tlaskalova-Hogenova $H$. Caco-2 cell monolayer integrity and effect of probiotic Escherichia coli Nissle 1917 components. Neuro Endocrinol Lett 2010; 31: 51-6.

[29] Johnson-Henry KC, Hagen KE, Gordonpour M, Tompkins TA, Sherman PM. Surface-layer protein extracts from Lactobacillus helveticus inhibit enterohaemorrhagic Escherichia coli O157:H7 adhesion to epithelial cells. Cell Microbiol 2007; 9: 356-67.

[30] Lewis K, Lutgendorff F, Phan V, Soderholm JD, Sherman PM, McKay DM. Enhanced translocation of bacteria across metabolically stressed epithelia is reduced by butyrate. Inflamm Bowel Dis. 2010; 16: 1138-48.

[31] Collado MC, Meriluoto J, Salminen S. Role of commercial probiotic strains against human pathogen adhesion to intestinal mucus. Lett Appl Microbiol 2007; 45: 454-60.

[32] Collado MC, Grzeskowiak L, Salminen S. Probiotic strains and their combination inhibit in vitro adhesion of pathogens to pig intestinal mucosa. Curr Microbiol 2007; 55: 260-5.

[33] Sherman PM, Johnson-Henry KC, Yeung HP, Ngo PS, Goulet J, Tompkins TA. Probiotics reduce enterohemorrhagic Escherichia coli O157:H7- and enteropathogenic E. coli O127:H6-induced changes in polarized T84 epithelial cell monolayers by reducing bacterial adhesion and cytoskeletal rearrangements. Infect Immun 2005; 73: 5183-8.

[34] Lebeer S, Vanderleyden J, De Keersmaecker SC. Host interactions of probiotic bacterial surface molecules: comparison with commensals and pathogens. Nat Rev Microbiol 2010; 8: 171-84.

[35] Kankainen M, Paulin L, Tynkkynen S, et al. Comparative genomic analysis of Lactobacillus rhamnosus GG reveals pili containing a human- mucus binding protein. Proc Natl Acad Sci USA 2009; 106: $17193-8$.

[36] Mukai T, Kaneko S, Matsumoto M, Ohori H. Binding of Bifidobacterium bifidum and Lactobacillus reuteri to the carbohydrate moieties of intestinal glycolipids recognized by peanut agglutinin. Int J Food Microbiol 2004; 90: 357-62. 
[37] Tallon R, Arias S, Bressollier P, Urdaci MC. Strain- and matrixdependent adhesion of Lactobacillus plantarum is mediated by proteinaceous bacterial compounds. J App Microbiol 2006; 102: 442-51.

[38] Otte JM, Podolsky DK. Functional modulation of enterocytes by gram-positive and gram-negative microorganisms. Am J Physiol Gastrointest Liver Physiol 2004; 286: G613-26.

[39] Lutgendorff F, Nijmeijer RM, Sandstrom PA, et al. Probiotics prevent intestinal barrier dysfunction in acute pancreatitis in rats via induction of ileal mucosal glutathione biosynthesis. PLoS ONE 2009; 4: e4512.

[40] Resta-Lenert S, Barrett KE. Probiotics and commensals reverse TNF-alpha- and IFN-gamma-induced dysfunction in human intestinal epithelial cells. Gastroenterology 2006; 130: 731-46.

[41] Madsen K, Cornish A, Soper P, et al. Probiotic bacteria enhance murine and human intestinal epithelial barrier function. Gastroenterology 2001; 12: 580-91.

[42] Madsen KL, Lewis SA, Tavernini MM, Hibbard J, Fedorak RN. Interleukin 10 prevents cytokine-induced disruption of T84 monolayer barrier integrity and limits chloride secretion. Gastroenterology 1997; 113: 151-9.

[43] Bruewer M, Luegering A, Kucharzik T, et al. Proinflammatory cytokines disrupt epithelial barrier function in an apoptosisindependent mechanism. J Immunol 2003; 171: 6164-72.

[44] Mankertz J, Tavalali S, Schmitz H, et al. Expression from the human occludin promoter is affected by tumor necrosis factor alpha and interferon gamma. J Cell Sci 2000; 113: 2085-90.

[45] Seth A, Yan F, Polk DB, Rao RK. Probiotics ameliorate the hydrogen peroxide-induced epithelial barrier disruptionby a PCK and MAP Kinase dependent mechanism. Am J Physiol Gastrointest Liver Physiol 2008; 294:G1060-9.

[46] Resta-Lenert SC, Barrett KE. Modulation of intestinal barrier properties by probiotics: role in reversing colitis. Ann N Y Acad Sci 2009; 1165: 175-82.
[47] Fujiya M, Musch MW, Nakagawa Y, et al. The Bacillus subtilis quorum-sensing molecule CSF contributes to intestinal homeostasis via OCTN2, a host cell membrane transporter.[see comment]. Cell Host Microbe 2007; 1: 299-308.

[48] Yan F, Polk DB. Probiotic bacterium prevents cytokine-induced apoptosis in intestinal epithelial cells. J Biol Chem 2002; 277 50959-65.

[49] Yan F, Cao H, Cover TL, Whitehead R, Washington MK, Polk DB. Soluble proteins produced by probiotic bacteria regulate intestinal epithelial cell survival and growth. Gastroenterology 2007; 132: 562-75.

[50] Arrieta MC, Bistritz L, Meddings JB. Alterations in intestinal permeability. Gut 2006; 55:1512-20.

[51] Arnott ID, Kingstone K, Ghosh S. Abnormal intestinal permeability predicts relapse in inactive Crohn disease. Scand J Gastroenterol 2000; 35: 1163-9.

[52] Johansson JE, Brune M, Ekman T. The gut mucosa barrier is preserved during allogeneic, haemopoietic stem cell transplantation with reduced intensity conditioning. Bone Marrow Transplant 2001; 28: 737-42.

[53] Vaarala O. Leaking gut in type 1 diabetes. Curr Opin Gastroenterol 2008; 24: 701-6.

[54] DeMeo MT, Mutlu EA, Keshavarzian A, Tobin MC. Intestinal permeation and gastrointestinal disease. J Clin Gastroenterol 2002; 34: 385-96.

[55] Holland J, Carey M, Hughes N, et al. Intraoperative splanchnic hypoperfusion, increased intestinal permeability, down-regulation of monocyte class II major histocompatibility complex expression, exaggerated acute phase response, and sepsis. Am J Surg 2005; 190: 393-400.

[56] Iannitti T, Palmieri B. Therapeutical use of probiotic formulations in clinical practice. Clin Nutr 2010; 29: 701-25.

(C) Karen L. Madsen; Licensee Bentham Open.

This is an open access article licensed under the terms of the Creative Commons Attribution Non-Commercial License (http://creativecommons.org/licenses/ by-nc/3.0/) which permits unrestricted, non-commercial use, distribution and reproduction in any medium, provided the work is properly cited. 